\title{
Real-world experience with letermovir in primary prophylaxis of cytomegalovirus in adult patients after hematopoietic cell transplantation: summary of reported data
}

\author{
Krzysztof Czyżewski ${ }^{\star}$, Jan Styczyński iD \\ Department of Pediatric Hematology and Oncology, Collegium Medicum, Nicolaus Copernicus University Torun, \\ Antoni Jurasz University Hospital in Bydgoszcz, Bydgoszcz, Poland
}

\begin{abstract}
Introduction: Letermovir (LMV) is a new antiviral agent approved in 2017 for prophylaxis to prevent cytomegalovirus (CMV) reactivation in CMV-seropositive allogeneic hematopoietic cell transplant recipients. Numerous reports on real-world experiences with LMV have been presented at international hematology and hematopoietic cell transplantation meetings. The objective of this study was to summarize data reported 2019-2020 on primary prophylaxis with LMV in adult patients.
\end{abstract}

Methods: We analyzed 19 studies published or presented in 2019 and 2020, including two studies presented twice.

Results: An overall 817 patients received primary prophylaxis with LMV. In 12 studies with a control group, the rate of breakthrough infection was $99 / 577$ (17.2\%) vs. 874/1,525 (57.3\%), odds ratio (OR) $=6.5$ [95\% confidence interval (Cl) $=5.1-8.2), p<0.0001]$. In seven studies without a control group, the rate was $17 / 240$ (7.1\%). Overall breakthrough infection occurred in 116/817 (14.2\%) patients on LMV primary prophylaxis vs. 874/1,525 (57.3\%) without prophylaxis, $\mathrm{OR}=8.1(95 \% \mathrm{Cl}=6.5-10.1), p<0.0001$.

Conclusions: LMV when used for primary prophylaxis challenges the standard of care for CMV reactivation based on preemptive therapy. Presented real-world data shows a significant improvement in reducing the risk of any CMV viremia and clinically significant CMV infection in all reported studies performed so far. LMV is a drug that breaks the paradigm of preventive therapy by moving it from pre-emptive treatment to prophylaxis.

Key words: cytomegalovirus, letermovir, prophylaxis, preemptive therapy, hematopoietic cell transplantation

Acta Haematologica Polonica 2021; 52, 3: 182-189

\section{Introduction}

\section{Antiviral anti-CMV prophylaxis}

To prevent cytomegalovirus (CMV) disease in allogeneic hematopoietic cell transplantation (allo-HCT) recipients, early CMV replication should be prevented. It has been shown that the presence of any CMV viremia contributes to non-relapse mortality (NRM) and all-cause mortality in the early and late post-transplant periods up to one year after HCT, even with preemptive therapy [1]. The rationale for the use of prophylaxis against CMV infection (CMVi) after allo-HCT is the observation that CMV replication increases mortality, while CMV seropositivity of the recipient significantly reduces overall survival (OS) [2-4].

\footnotetext{
*Address for correspondence: Krzysztof Czyżewski, Department of Pediatric Hematology and Oncology, Collegium Medicum in Bydgoszcz, Nicolaus Copernicus University in Toruń, Skłodowskiej-Curie 9, 85-094 Bydgoszcz, Poland, phone: +48525854860, fax: +485258540 87, e-mail: k.czyzewski@cm.umk.pl

\section{PTHiT Copyright $\odot 2021$ The Polish Society of Haematologists and Transfusiologists, Insitute of Haematology and Transfusion Medicine. All rights reserved.}


In an allo-HCT setting, prophylaxis of CMV infection usually has not been used to date due to the high rate of nephro- and myelotoxicity of available anti-CMV drugs, and the possibility of postponed onset of CMVi and CMV disease after prophylaxis discontinuation. Also, previous studies have described the risk of development of drug resistance or intolerance, delayed CMV-specific immune reconstitution, and finally no improvement in OS. Additionally, unsuccessful trials with maribavir (MBV) [5] and brincidofovir (BCV) [6] used as a prophylaxis have shown that improvement is difficult. Unnecessary treatment of patients who neither develop CMVi nor CMV disease is the main pitfall of a prophylaxis strategy.

However, a successful phase III study with letermovir (LMV) in prophylaxis [7] has changed the landscape and opened up the possibility of a very safe and effective approach. Consequently, the current recommendations of the $7^{\text {th }}$ European Conference on Infection in Leukemia (ECIL-7) on prophylaxis of CMV in allo-HCT setting [8] include: letermovir (with highest grade of recommendation) [7], valacyclovir $[9,10]$ (in association with preemptive strategy), acyclovir [11] (less efficient than valacyclovir), and gancyclovir $[12,13]$, while foscarnet is not recommended for anti-CMV prophylaxis [14, 15].

Gancyclovir, valgancyclovir, cidofovir, foscarnet, acyclovir and valacyclovir are currently available antivirals with anti-CMV potential. Three new antiviral agents have emerged recently, enhancing the ability to prevent and treat CMV, namely LMV, MBV and BCV. In phase II studies, LMV, MBV and BCV were effective [16-18], although this was not confirmed in phase III studies for MBV [5] and BCV [6].

At present, LMV is approved in Europe and the US for prophylaxis, while studies on the roles of MBV and BCV are ongoing. MBV is close to being given European Medicine Agency (EMA) and Food and Drug Agency (FDA) licenses, as studies show that it is effective in preemptive treatment and in refractory and recurrent CMVi $[19,20]$.

\section{Letermovir}

CMV for replication involves viral terminase cleaving of concatemeric genomic viral DNA which is located to intended viral capsids. CMV replication is inhibited by LMV, which binds to the complex of viral terminase [7]. In vitro and in vivo studies have shown its specific anti-CMV activity with no activity contrary to other viruses, and no cross-resistance with other medicines applied in the treatment of CMV disease [21]. LMV is a 3,4-dihydro-quinazoline-4-yl-acetic acid derivative and belongs to a new class of antivirals [21]. The bioavailability in healthy individuals is $94 \%$, when administered orally.

However, in allogeneic HCT patients, LMV bioavailability is $85 \%$ with simultaneous cyclosporine administration, and decreases to $35 \%$ without cyclosporine. In $93 \%$ it is excreted in faeces, and in $70 \%$ as unchanged drug. In cases of renal insufficiency, there is no need for dose adjustments due to minimal renal excretion [22].

Currently, the EMA and FDA approve LMV for prophylaxis of CMV in allo-HCT patients, while LMV has not been approved for: secondary prophylaxis of CMVi, preemptive treatment of asymptomatic CMVi, or treatment of CMV disease, including those resistant to gancyclovir. There is also no registration for its use in children.

Numerous reports on real-world experiences with letermovir have been presented to international hematology and HCT meetings. The objective of this study was to summarize data reported in 2019-2020 on the use of letermovir in primary prophylaxis in adults.

\section{Methods}

\section{Design of study}

We analyzed studies on primary prophylaxis with LMV in adult patients published in 2019 and 2020, and abstracts from international hematology and HCT meetings held in 2019-2020 including the American Society of Transplantation and Cellular Therapy (ASTCT/TCT), the European Society of Blood and Marrow Transplantation (EBMT), and the American Society of Hematology (ASH). The following data was retrieved from these reports: number of patients treated with LMV; number of patients with clinically significant CMV infection which required preemptive treatment; day of beginning LMV prophylaxis; and definition of high-risk patients, if available. For some abstracts, data on a control group not treated with LMV was also available.

\section{Definitions}

CMV infection (CMVi) was defined when the virus, its antigens (proteins) or genetic material were present in any tissue or body fluid. Clinically significant CMVi (cs-CMVi) was defined as viremia that required the use of antiviral compound, usually as a pre-emptive therapy.

\section{Patients at high risk of CMV reactivation}

In the pivotal phase III study by Marty et al. [7], patients at high risk of CMV reactivation and CMV disease were defined as meeting one or more of the following criteria at the time of randomization: having an unrelated donor with at least one mismatch at one of the specified four human leukocyte antigen (HLA) gene loci (HLA-A, B, C, and DRB1); having a related donor with at least one mismatch at one of the specified three HLA gene loci (HLA-A, B, or $\mathrm{DR}$ ); having a haploidentical (haplo) donor; the use of ex vivo T-cell-depleted grafts; the use of umbilical cord blood as the hematopoietic-cell source; and having graft-versus-host disease (GvHD) of grade 2 or greater that led to the use of $1 \mathrm{mg}$ or more of prednisone (or its equivalent) per kilogram of body weight per day. Other patients not fulfilling high-risk criteria were considered to be the low-risk group. 
Table I. Summary of reported data in abstracts and full papers on primary prophylaxis with LMV in 2019-2020 with control group

\begin{tabular}{|c|c|c|c|c|c|c|c|c|}
\hline No. & Study reference & $\begin{array}{c}\text { Number } \\
\text { of } \\
\text { patients }\end{array}$ & Characteristics & $\begin{array}{l}\text { High-risk } \\
\text { patients }\end{array}$ & $\begin{array}{l}\text { Start } \\
\text { of } \\
\text { LMV }\end{array}$ & $\begin{array}{l}\text { No. of pts with } \\
\text { CMVi on LMV vs. } \\
\text { total no. of pts } \\
\text { on LMV }\end{array}$ & $\begin{array}{l}\text { No. of pts with CMVi } \\
\text { in control group vs. } \\
\text { no. of pts in control } \\
\text { group }\end{array}$ & $\begin{array}{l}\text { Study } \\
\text { type }\end{array}$ \\
\hline 1. & Lau et al. (A1) & 10 & CMV R+ CBT & N/D & +7 & $0 / 10(0 \%)$ & $51 / 62(82.3 \%)$ & PS \\
\hline 2. & Foolad et al. (A3) & 53 & CMV R+ & N/D & N/A & $11 / 53(21 \%)$ & $11 / 21(52.4 \%)$ & RS \\
\hline 3. & Dadwal et al. (A7) & 59 & CMV R+ & $\begin{array}{l}\text { Haplo, CBT, } \\
\text { ATG }\end{array}$ & +13 & $13 / 59(22.4 \%)$ & $126 / 307(41.1 \%)$ & RS \\
\hline 4. & Shigle et al. (A4) & 53 & CMV R+ & N/D & $\mathrm{N} / \mathrm{A}$ & $11 / 53$ (21\%) & $11 / 21(52 \%)$ & RS \\
\hline 5. & Karam et al. (A13) & 63 & $\begin{array}{l}\text { Haplo, MUD, } \\
\text { CBT, ATG }\end{array}$ & N/D & N/A & $12 / 63$ (19.4\%) & $28 / 41$ (68.3\%) & RS \\
\hline 6. & Sharma et al. [23] & 32 & $\begin{array}{c}\text { CMV R+ CBT } \\
\text { (double/haplo) }\end{array}$ & N/D & 0 & $0 / 32(0 \%)$ & $15 / 101$ (14.9\%) & RS \\
\hline 7. & $\begin{array}{l}\text { Anderson et al. } \\
\text { (A14) [26] }\end{array}$ & 25 & $\begin{array}{l}\text { CMV R+, haplo, } \\
\text { MMUD, CBT, } \\
\text { GvHD + predni- } \\
\text { sone >1 mg/kg }\end{array}$ & N/D & +10 & $1 / 25(4 \%)$ & $63 / 106(59.4 \%)$ & PS \\
\hline 8. & $\begin{array}{l}\text { Dominietto et al. } \\
\text { (A17) }\end{array}$ & 30 & CMV R+ & N/D & +14 & $0 / 30(0 \%)$ & $71 / 157(45.2 \%)$ & RS \\
\hline 9. & Mori Y et al. (A18) & 114 & CMV R+ & $\begin{array}{l}\text { MMUD/ } \\
\text { /MMRD, } \\
\text { CBT, GvHD } \\
\text { treated with } \\
\text { steroids }\end{array}$ & N/A & $34 / 114(29.8 \%)$ & $428 / 571$ (74.9\%) & RS \\
\hline 10. & $\begin{array}{l}\text { Satake et al. (A19; } \\
\text { A12) }\end{array}$ & 27 & $\begin{array}{c}\text { Haplo, MMUD, } \\
\text { CBT }\end{array}$ & N/D & 0 & $3 / 27$ (11.1\%) & $15 / 27(55.6 \%)$ & RS \\
\hline 11. & $\begin{array}{l}\text { Derigs et al. (A20; } \\
\text { A10) [25] }\end{array}$ & 80 & CMV R+ & N/D & N/A & $11 / 80(14 \%)$ & $33 / 80$ (41.2\%) & RS \\
\hline 12. & $\begin{array}{l}\text { Jinnouchi et al. } \\
\text { (A21) }\end{array}$ & 31 & $\begin{array}{c}\text { CMV R+ } \\
\text { (MMUD, CBT, } \\
\text { ATG) }\end{array}$ & N/D & N/A & $3 / 31(9.7 \%)$ & 22/31 (71.0\%) & RS \\
\hline \multicolumn{6}{|c|}{ TOTAL } & 99/577 (17.2\%) & $874 / 1,525(57.3 \%)$ & \\
\hline
\end{tabular}

CMVi - significant cytomegalovirus infection; HCT - hematopoietic cell transplantation; CBT - cord blood transplantation; MUD - matched unrelated donor; MMUD - mismatched unrelated donor; MMRD - mismatched related donor; haplo - haploidentical HCT; R+ - seropositive recipient; ATG - anti-thymocyte globulin; N/A - not available; N/D - not defined; PS - prospective study; RS - retrospective study

\section{Statistical analysis}

Odds ratio (OR) with $95 \%$ of confidence interval $(95 \% \mathrm{Cl})$ were calculated in order to compare rates of categoric variables in analyzed groups.

\section{Results}

We analyzed real-world practice on primary prophylaxis with LMV for prevention of CMV in adult allo-HCT recipients. Data published or presented at major hematological conferences (ASTCT/TCT, EBMT, and ASH) in 2019-2020, supplemented with two papers published in 2019 [23-25], was reviewed.

Overall, we found and analyzed 19 reports on primary prophylaxis with LMV conferred in 2019 and 2020, including two studies presented twice. We did not find any other conference materials in this field. 817 patients on primary prophylaxis with LMV were described (Tables I, II).
In 12 studies with a control group, the rate of breakthrough infection was $99 / 577$ (17.2\%) vs. 874/1,525 (57.3\%), with odds ratio $\mathrm{OR}=6.5(95 \% \mathrm{Cl}=5.1-8.2), p \leq 0.0001$. In seven studies without a control group, the rate was $17 / 240$ (7.1\%). Overall breakthrough infection occurred in $116 / 817(14.2 \%)$ patients on LMV primary prophylaxis vs. $874 / 1,525(57.3 \%)$ without prophylaxis, OR $=8.1(95 \%$ $\mathrm{Cl}=6.5-10.1), p \leq 0.0001$.

\section{Discussion}

Real-world experience with LMV shows significant reductions of CMVi and Cs-CMVi in presented studies contrary to any control, usually historical. In presented studies, a highly effective LMV prophylaxis decreased the need for the use of toxic anti-CMV therapies. It also contributed to decreased CMV-related mortality, while no significant 
Table II. Summary of reported data in abstracts and full papers on primary prophylaxis with LMV in 2019-2020 without control group

\begin{tabular}{|c|c|c|c|c|c|c|c|c|}
\hline No. & $\begin{array}{l}\text { Study refe- } \\
\text { rence }\end{array}$ & $\begin{array}{l}\text { Number } \\
\text { of } \\
\text { patients }\end{array}$ & Characteristics & $\begin{array}{l}\text { High-risk } \\
\text { patients }\end{array}$ & $\begin{array}{l}\text { Start } \\
\text { of } \\
\text { LMV }\end{array}$ & $\begin{array}{l}\text { No. of pts with } \\
\text { CMVi on LMV } \\
\text { vs. total no. } \\
\text { of pts on LMV }\end{array}$ & Comments & $\begin{array}{l}\text { Study } \\
\text { type }\end{array}$ \\
\hline 1. & $\begin{array}{l}\text { Merchant } \\
\text { et al. (A5) }\end{array}$ & 30 & $\begin{array}{l}\text { CMV R+ and or D+ } \\
\text { Haplo, CBT, MUD }\end{array}$ & $\mathrm{N} / \mathrm{D}$ & +14 & $6 / 30(20.8 \%)$ & $\begin{array}{l}\text { Authors provided data on histo- } \\
\text { ric control group with infection } \\
\text { rate of } 63 \% \text {, but no more deta- } \\
\text { ils provided }\end{array}$ & RS \\
\hline 2. & $\begin{array}{l}\text { Ferrari } \\
\text { et al. (A6) }\end{array}$ & 22 & CMV R+ and/or D+ & N/D & +5 & $0 / 22(0 \%)$ & & RS \\
\hline 3. & $\begin{array}{l}\text { Lin et al. } \\
(A 2 ; A 8) \\
{[24]}\end{array}$ & 39 & CMV R+ & $\begin{array}{l}\text { TCD, } \\
\text { haplo, } \\
\text { MMUD/ } \\
\text { /MMRD }\end{array}$ & +7 & $2 / 39$ (5.1\%) & $\begin{array}{c}1 / 27(3.7 \%) \text { in high-risk and } \\
1 / 12(8.3 \%) \text { in low-risk }\end{array}$ & RS \\
\hline 4. & $\begin{array}{l}\text { Robin et al. } \\
\text { (A9) }\end{array}$ & 22 & $\begin{array}{l}\text { CMV R+, haplo, } \\
\text { CBT, GvHD, ATG }\end{array}$ & $\mathrm{N} / \mathrm{D}$ & $\mathrm{N} / \mathrm{A}$ & $0 / 22(0 \%)$ & & RS \\
\hline 5. & $\begin{array}{l}\text { Kodiyan- } \\
\text { plakkal } \\
\text { et al. (A11) }\end{array}$ & 31 & $\begin{array}{c}\text { CMV R+, ATG, anti- } \\
\text {-CD52 }\end{array}$ & N/D & N/A & 1/31 (3.2\%) & & RS \\
\hline 6. & $\begin{array}{l}\text { Patel et al. } \\
\text { (A15) }\end{array}$ & 20 & CMV R+ haplo & N/D & +16 & $5 / 20(25 \%)$ & & RS \\
\hline 7. & $\begin{array}{l}\text { Nguyen } \\
\text { et al. (A16) }\end{array}$ & 76 & $\begin{array}{l}\text { Haplo, CBT, ATG, } \\
\text { MUD, MMRD }\end{array}$ & N/D & N/A & 3/76 (3.9\%) & $\begin{array}{l}\text { Authors provided data on histo- } \\
\text { ric control group with infection } \\
\text { rate } 48 / 553(8.7 \%) \text {, but some } \\
\text { of them treated with other an- } \\
\text { tivirals }\end{array}$ & PS \\
\hline \multicolumn{6}{|c|}{ TOTAL } & $17 / 240$ (7.1\%) & & \\
\hline
\end{tabular}

CMVi - significant cytomegalovirus infection; HCT - hematopoietic cell transplantation; CBT - cord blood transplantation; MUD - matched unrelated donor; MMUD - mismatched unrelated donor; MMRD mismatched related donor; haplo - haploidentical HCT; R+ - seropositive recipient; ATG - anti-thymocyte globulin; N/A - not available; N/D - not defined, PS - prospective study, RS - retrospective study

adverse effect of LMV, especially myelosuppression, was observed.

Patients on LMV prophylaxis had lower incidence of cs-CMVi ( $21 \%$ vs. $52 \%, p=0.01)$, descending trend in frequency of CMV disease ( $6 \%$ vs. $10 \%, p=0.55$ ), fewer hospitalizations for treatment of CMVi ( $7 \%$ vs. $12 \%, p=0.57$ ), and lower all-cause mortality assessed at day $+100(4 \%$ vs. $14 \%, p=0.1$ ) (A3).

Multivariate analysis has shown that two factors had an impact on the occurrence of cs-CMVi at day +100 : treatment of GVHD increased the risk, while administration of LMV decreased it.

Another important observation performed in this study was that LMV had a significantly stronger positive effect than the negative effect of graft-versus-host disease. Only LMV use influenced the risk of any CMV-DNA detection, while other factors such as transplantation type and CMV donor serostatus had no effect on Cs-CMVi and CMV viremia (A3).

Patients who were on LMV for prophylaxis had less cs-CMVi, fewer episodes of CMVi (21\% vs. 52\%, $p=0.01)$, and a trend towards lower all-cause mortality by day +100 (A4). In another study, the efficacy of LMV in a real-world setting for prevention of cs-CMV during the first 14 weeks after alIo-HCT in CMV-seropositive patients compared to control group ( $0 \%$ vs. $45 \%$ respectively, $p<0.0001$ ) was observed, with no serious adverse event of LMV prophylaxis (A17). LMV significantly reduced the risk of CMV reactivation in high-risk patients compared to historical control group (20\% vs. $63 \%, p=0.003$ ) (A5).

The cumulative incidence of CMV reactivation within 100 days post-HCT was lower in the LMV group versus control group ( $20 \%$ vs. $72 \%$ respectively, $p \leq 0.001$ ) as well as 100-day cumulative incidence of cs-CMVi (4\% vs. $59 \%$ respectively, $p \leq 0.001$ ) with no CMV invasive disease. This beneficial effect on reduction of $\mathrm{cs}-\mathrm{CMVi}$ was also observed at day +200 in the LMV group, which suggests sustained efficacy after discontinuation of prophylaxis. However, no difference in mortality was observed between LMV group and control group (20\% vs. 21\%, $p=0.79$ ) in the first 100 days post-HCT. Further studies are needed to investigate the role of LMV beyond 100 days post-HCT (A14) [26].

Compared to the control group, LMV reduced frequency of CMV reactivation in high-risk allo-HCT patients $(9.7 \%$ vs. $71 \%$ respectively, $p \leq 0.001$ ). The authors suggest that LMV 
in prophylaxis probably reduces treatment-related mortality directly by CMV disease suppression, but also indirectly by incidence reduction of other transplant complications such as acute graft-versus-host disease (A21).

Recently published data suggests that LMV use in the initial period after HCT significantly inhibits CMVi (A12, A19), especially in high-risk patients (T-cell depleted allo-HCT recipients) (A11).

LMV was safe and significantly lowered the cumulative incidence of CMV reactivation. In CMV seropositive alIo-HCT recipients, the use of LMV significantly decreased the cost of therapy of CMVi correlated with valgancyclovir and foscarnet administration (A20, A10).

Other studies have shown that LMV was effective and well tolerated in primary prophylaxis lasting 14 weeks or longer just after allo-HCT or as a secondary prophylaxis. However, to obtain the optimal time of prophylaxis in high-risk allo-HCT patients, additional studies should be undertaken (A8, A2).

It has been shown that LMV prophylaxis had a beneficial effect on the reduction of risk of Cs-CMVi in CMV-seropositive unselected, mostly high-risk, transplant recipients. However, contrary to the study by Marty et al. [7], just a few CMVi occurring after day +100 since discontinuation of LMV prophylaxis were seen. Also, no differences in time to neutrophil or platelet recovery, incidence of relapse, acute GvHD, OS and NRM were observed (A13).

There was no CMV reactivation in all 22 high-risk patients, with only $1 / 35$ (3\%) patients on secondary prophylaxis developing breakthrough infection. LMV may provide a safe bridge between preemptive therapy and specific immune reconstitution (A9). In high-risk patients, LMV for primary prophylaxis was well tolerated without hematopoietic/ /organ toxicity. CMV viremia occurred in $71 \%$ of patients on LMV and in $74 \%$ in the control group, however $34 \%$ of patients on LMV prophylaxis started this prophylaxis on a different CMV-active agent compared to $50 \%$ of controls. LMV prophylaxis decreased the burden of CMV, and only $3.9 \%$ of patients on LMV developed disease, compared to $8.7 \%$ in the control group (A16).

Compared to alternative prophylaxis approaches in patients after cord blood transplants (CBT) through day +100 , LMV is safe and effective. No additional CMV-directed treatment has been used in patients during LMV prophylaxis [23]. LMV was well tolerated with no drug toxicities in adult patients after CBT with a simultaneous cost decrease in this group of patients (A1).

In patients after CBT, CMV can reactivate very early [27], which is why prophylaxis with LMV should be started on the day of transplantation, with no negative influence on time of engraftment or graft failure [23]. However, one potential problem, especially in CBT recipients, is postponed CMV reactivation after cessation of LMV prophylaxis [23]. That is why it has been postulated to treat LMV patients and recommend serial CMV monitoring at least monthly through six months post-transplantation [23].

In CMV-seropositive haplo-HCT recipients on LMV primary prophylaxis, CMV reactivation occurred in $25 \%$ of patients before day +100 , and an additional $27 \%$ had CMV reactivation after $L M V$ was discontinued at day +100 . However, significant $\mathrm{CMV}$ reactivation was not seen beyond day +100 , and future studies need to be conducted on the ideal duration of prophylaxis in this high-risk population (A15).

In the study by Dadwal et al. (A7), the high-risk patient group was defined as CMV-seropositive haplo-HCT recipients, CBT-recipients, and patients using anti-thymocyte globulin (ATG), whereas all others were regarded as the low risk group. Patients on LMV had lower rate of CMVi than control group ( $22.4 \%$ vs. $41.1 \%, p=0.008$ ), but the benefit was greater in high-risk HCT patients $(22.2 \%$ vs. $62.8 \%$, $p=0.004)$ than in low-risk patients $(22.8 \%$ vs. $35.6 \%$, $p=0.11$ ) with LMV prophylaxis. In the LMV group, clinically significant $\mathrm{CMV}$ infections requiring preemptive therapy occurred in $8.4 \%(n=5)$; when excluding two patients who were not on $\mathrm{LMV}$ at the time of $\mathrm{CMVi}$, the rate was $5 \%$. The low level of CMVi $(<2,500 \mathrm{IU} / \mathrm{mL})$ in most patients resolved spontaneously with continued LMV prophylaxis with no need for treatment of CMVi.

Mori et al. (A18) among CMV-seropositive recipients distinguished mismatched unrelated donors (MMUD), CBT or systemic treatment for GVHD as a high-risk group. The cumulative incidence of Cs-CMVi was significantly lower in LMV patients than in non-LMV patients $(29.8 \%$ vs. $74.9 \%$, $p<0.0001)$. This welcome decrease is mirrored in recipients with a high risk of CMV reactivation rather than a low risk (LMV vs. non-LMV: high-risk group $34.1 \%$ vs. $81.8 \%$, respectively, $p<0.001$, low-risk group $15.4 \%$ vs. $50.4 \%$ respectively, $p=0.076$ ) (A18).

In the study by Lin et al. (A2; A8), primary LMV prophylaxis was introduced before day +7 after HCT in a high-risk group and before day +28 after HCT in low-risk patients. Clinically significant CMV reactivation without disease occurred in 2/39 (5\%) patients, including only one patient (i.e. 2.5\%; HR 1/27, LR 0/12) at 14 weeks after allo-HCT. The other patient (after a second allogeneic transplantation), presented breakthrough CMV reactivation after short-term off-drug treatment. Around day +100 , UL56 mutation was diagnosed, followed by cure with valgancyclovir. Only in this one patient, in whom prolonged LMV primary prophylaxis was given, was cs-CMV observed.

As delayed CMV reactivation after prophylaxis discontinuation is controversial, screening for CMV reactivation beyond day +100 should be obligatory. Further studies on prolonged prophylaxis after day +100 should be conducted in patients after CBT (A1) and on immunosuppressive treatment of graft-versus-host disease. All demonstrated benefits should prompt consideration of LMV prophylaxis in all CMV-seropositive allo-HCT recipients (A3). 


\section{Conclusions}

Real-world data has confirmed the results of the pivotal study by Marty et al. [7] on primary prophylaxis with LMV in adult CMV-seropositive recipients of allo-HCT. It has been shown that the use of LMV is safe and effective for prophylaxis in this group of patients. There has been no delay observed in hematological recovery in any published report. Moreover, HCT patients with a high risk of CMV reactivation (i.e. recipients of $C B T$, haplo, MMUD and with ATG use) had a more beneficial effect with LMV prophylaxis than did other patients. In high-risk patients, a positive effect of prolonged LMV administration is appreciable, but the objective duration of its use requires further studies.

Compared to preemptive therapy [7], LMV was much more effective in preventing CMV infection and CMV disease. The real-world experience shows that LMV does not cause myelotoxicity and has a beneficial safety profile. Simultaneously, prophylaxis with LMV improves OS during the first 24 and 48 weeks after HCT [7, 28-30].

All these findings indicate that in CMV-seropositive patients after HCT, a preventive strategy based on preemptive therapy could be successfully shifted to a prophylaxis strategy. Such a prophylaxis strategy results in a reduction of cs-CMVi, a decreased need for preemptive treatment and hospitalizations, and contributes to lower all-cause mortality. In addition, a prophylaxis strategy with LMV shows a potential benefit in reducing costs, especially in the context of negative effects decrease such as graft-versus-host disease or bacterial and fungal infections.

The recent approval of LMV for primary anti-CMV prophylaxis in adults challenges the current standard of care that is based on preemptive therapy. Real-world data shows a significant risk reduction of any CMV viremia or Cs-CMVi in all analyzed reports.

LMV is a drug that breaks the paradigm of anti-CMV management by shifting preventive therapy to prophylaxis. Additionally, recent studies have indicated needs for prophylaxis in children [31] and secondary prophylaxis [32].

\section{List of analyzed meeting abstracts}

TCT 2019. Abstracts from the 2019 TCT Meetings of ASBMT and CIBMTR, February 20-24, 2019 Houston, Texas. Biol Blood Marrow Transplant. 2019; 25(3): A4-S442 (Suppl):

- A1: Lau C, Politikos I, Maloy MA et al. Letermovir Prophylaxis demonstrates high efficacy in adult cytomegalovirus (CMV) seropositive cord blood transplant (CBT) recipients: a comparison with pre-letermovir era CBT controls. Biol Blood Marrow Transplant. 2019;25(3): S94-S95, doi.org/10.1016/j.bbmt.2018.12.182 (abstract \#127).

- A2: Lin A, Malloy MA, Bhatt V et. al. Letermovir in allogeneic hematopoietic cell transplantation: beyond the label. Biol Blood Marrow Transplant. 2019;25(3): S95-S96. doi.org/10.1016/j.bbmt.2018.12.183 (abstract \#128).
- A3: Foolad F, Shigle TS, Handy VH et al. A single center experience of letermovir for the prevention of CMV infection in CMV-seropositive allogeneic cell transplant (allo-HCT) recipients. Biol Blood Marrow Transplant. 2019;25(3): S275. doi.org/10.1016/j. bbmt.2018.12.339 (abstract \#396).

- A4: Shigle TL, Handy VW, Foolad F, et al. Breakthrough CMV Infections on letermovir prophylaxis in CMV-seropositive allogeneic hematopoeitic cell transplant (allo-HCT) Recipients Biol Blood Marrow Transplant. 2019;25(3): S276 (abstract \#398).

- A5: Merchant SL, Gatwood KS, Satyanarayanaet G et al. Efficacy and pharmacoeconomic impact of letermovir for CMV prophylaxis in allogeneic hematopoietic cell transplant recipients. Biol Blood Marrow Transplant. 2019;25(3): S280. doi.org/10.1016/j. bbmt.2018.12.349 (abstract \#406).

- A6: Ferrari A, Engemann AM, Saullo J. Preliminary outcomes of letermovir use for cytomegalovirus prophylaxis: a retrospective assessment at a single center. Biol Blood Marrow Transplant. 2019;25(3): S285 (abstract \#416).

- A7: Dadwal SS, Al Malaki MM, Yang D et al. Real world experience of letermovir (LTV) prophylaxis (Px) for the prevention of cytomegalovirus infection (CMVi) in the adult CMV seropositive recipients $(\mathrm{R}+)$ of allogeneic hematopoietic cell transplantation (HCT) Patients (pts). Biol Blood Marrow Transplant. 2019;25(3): S364. doi. org/10.1016/j.bbmt.2018.12.590 (abstract \#546).

EBMT 2019. Abstracts from the $45^{\text {th }}$ Annual Meeting of the European Society for Blood and Marrow Transplantation: physicians. Poster Session. Bone Marrow Transplant. 2019;54:144-619. https://doi.org/10.1038/s41409019-0559-4:

- A8: Lin A, Maloy MA, Bhatt V et al. Letermovir in hematopoietic cell transplantation: Beyond the label. Bone Marrow Transplant. 2019;54(Suppl 1): 405-406 (abstract \#P405).

- A9: Robin C, Ducastelle-Lepretre S, Thiebaut A et al. Letermovir for prophylaxis of cytomegalovirus (CMV) infection or disease in allogeneic HCT recipients: experience of secondary prophylaxis in the French compassionate program. Bone Marrow Transplant. 2019;54(Suppl 1): 406 (abstract \#P406).

- A10: Derigs P, Schubert ML, Schnitzler P et al. Real-world data on letermovir prophylaxis for cytomegalovirus reactivation after allogeneic hematopoietic cell transplantation: a single center experience. Bone Marrow Transplant. 2019;54(Suppl 1): 406-407 (abstract \#P407).

- A11: Kodiyanplakkal RP, Meown M, Guarneri D et al. Efficacy of letermovir prophylaxis in cytomegalovirus seropositive allogeneic hematopoietic stem cell transplant recipients receiving in-vivo T-cell depletion. Bone Marrow Transplant. 2019;54(Suppl 1): 419-420 (abstract \#P427). 
- A12: Satake A, Hotta M, Saito R et al. Efficacy of CMV prophylaxis with letermovir early after transplantation. Bone Marrow Transplant. 2019;54(Suppl 1): 448 (abstract \#P473).

ASH 2019. Abstract from $61^{\text {th }}$ Annual Meeting of American Society of Hematology. Orlando (December 7-10, 2019). Blood 2019;134(Suppl 1); November 13, 2019:

- A13: Karam E, LaPorte J, Sizemore C et al. Real world outcomes of letermovir prophylaxis in unselected high risk CMV seropositive hematopoietic stem cell transplant recipients. Blood 2019;134(Suppl 1): 3269. doi. org/10.1182/blood-2019-131365 (abstract \#3269).

TCT 2020. Abstracts from the 2019 TCT Meetings of ASBMT and CIBMTR, February 19-23, 2020 Orlando, Florida. Biol Blood Marrow Transplant. 2020;26(3): S256-S394:

- A14: Anderson A, Raja M, Morris M et al. Clinical "real-world" experience with letermovir for prevention of cytomegalovirus infection in allogeneic hematopoietic cell transplant recipients. Biol Blood Marrow Transplant. 2020;26(3)(Suppl): S317-S318. doi.org/10.1016/j. bbmt.2019.12.339 (abstract \#488).

- A15: Patel OS, Thomas E, Ganguly S et al. Letermovir for primary cytomegalovirus prevention in haploidentical stem cell transplant recipients. Biol Blood Marrow Transplant. 2020;26(3)(Suppl): S336. doi. org/10.1016/j.bbmt.2019.12.366 (abstract \#515).

- A16: Nguyen IT, Johnsrud JJ, Brown J et al. Letermovir prophylaxis in patients at high risk for CMV disease following hematopoietic cell transplant. Biol Blood Marrow Transplant. 2020;26(3)(Suppl): S347-S348. doi. org/10.1016/j.bbmt.2019.12.383 (abstract \#532).

EBMT 2020. Abstracts from the $46^{\text {th }}$ Annual Meeting of the European Society for Blood and Marrow Transplantation:

- A17: Dominietto A, Guarona G, Galano B et al. Primary letermovir prophylaxis in CMV seropositive patients undergoing allogeneic hematopoietic stem cell transplantation: real life experience (abstract \#B105).

- A18: Mori Y, Yoshimoto G, Eto E et al. Efficacy of letermovir for prophylaxis of CMV reactivation after allogeneic hematopoietic cell transplantation: a multi-center retrospective analysis among Japanese patients (abstract \#B130).

- A19: Satake A, Ichikawa J, Saito R et al. Clinical efficacy of letermovir prophylaxis for CMV infection after allogeneic hematopoietic stem cell transplantation: a single centre experience (abstract \#B143).

- A20: Derigs P, Schubert ML, Schnitzler P et at. Letermovir prophylaxis reduces inpatient resource consumption by being effective in preventing cytomegalovirus reactivation after allogeneic hematopoietic cell transplantation: a single center real-world experience (abstract \#B151).

- A21: Jonnuhi F, Katayama Y, Imanaka R et al. Versatile effects of letermovir prophylaxis for cytomegalovirus on allogeneic hematopoietic cell transplantation: a single-institution analysis (abstract \#B167).

\section{Authors' contributions}

KC, JS - study design, data analysis, manuscript writing, provision of important clinical data, data check-up and final approval of manuscript.

\section{Conflict of interest}

$\mathrm{KC}$ participated in meetings organized by MSD. JS has received lecture fees and participated in meetings organized by MSD.

\section{Financial support}

This research did not receive any specific grant from funding agencies in the public, commercial, or not-for-profit sectors.

\section{Ethics}

The work described in this article has been carried out in accordance with The Code of Ethics of the World Medical Association (Declaration of Helsinki) for experiments involving humans; EU Directive 2010/63/EU for animal experiments; Uniform requirements for manuscripts submitted to biomedical journals.

\section{References}

1. Green ML, Leisenring $\mathrm{W}, \mathrm{Xie} \mathrm{Hu}$, et al. Cytomegalovirus viral load and mortality after haemopoietic stem cell transplantation in the era of pre-emptive therapy: a retrospective cohort study. Lancet Haematol. 2016; 3(3): e119-e127, doi: 10.1016/S2352-3026(15)00289-6, indexed in Pubmed: 26947200.

2. Schmidt-Hieber M, Labopin M, Beelen D, et al. CMV serostatus still has an important prognostic impact in de novo acute leukemia patients after allogeneic stem cell transplantation: a report from the Acute Leukemia Working Party of EBMT. Blood. 2013; 122(19): 3359-3364, doi: 10.1182/blood-2013-05-499830, indexed in Pubmed: 24037724.

3. Ljungman P, Brand R, Hoek J, et al. Infectious Diseases Working Party of the European Group for Blood and Marrow Transplantation. Donor cytomegalovirus status influences the outcome of allogeneic stem cell transplant: a study by the European group for blood and marrow transplantation. Clin Infect Dis. 2014; 59(4): 473-481, doi: 10.1093/ /cid/ciu364, indexed in Pubmed: 24850801.

4. Styczyński J. ABC of viral infections in hematology: focus on herpesviruses. Acta Haematol Pol. 2019; 50(3): 159-166, doi: 10.2478/ ahp-2019-0026.

5. Marty FM, Ljungman P, Papanicolaou GA, et al. Maribavir $1263-300$ Clinical Study Group. Maribavir prophylaxis for prevention of cytomegalovirus disease in recipients of allogeneic stem-cell transplants: a phase 3, double-blind, placebo-controlled, randomised trial. Lancet Infect Dis. 2011; 11(4): 284-292, doi: 10.1016/S1473-3099(11)70024-X, indexed in Pubmed: 21414843.

6. Marty FM, Winston DJ, Chemaly RF, et al. SUPPRESS Trial Clinical Study Group. A randomized, double-blind, placebo-controlled phase 3 trial of oral brincidofovir for cytomegalovirus prophylaxis in allogeneic hematopoietic cell transplantation. Biol Blood Marrow Transplant. 2019; 25(2): 369-381, doi: 10.1016/j.bbmt.2018.09.038, indexed in Pubmed: 30292744.

7. Marty FM, Ljungman PT, Chemaly RF, et al. Letermovir Prophylaxis for Cytomegalovirus in Hematopoietic-Cell Transplantation. N Engl J Med. 2017; 377(25): 2433-2444, doi: 10.1056/NEJMoa1706640, indexed in Pubmed: 29211658. 
8. Ljungman P, de la Camara R, Robin C, et al. 2017 European Conference on Infections in Leukaemia group. Guidelines for the management of cytomegalovirus infection in patients with haematological malignancies and after stem cell transplantation from the 2017 European Conference on Infections in Leukaemia (ECIL 7). Lancet Infect Dis. 2019; 19(8): e260-e272, doi: 10.1016/S1473-3099(19)30107-0, indexed in Pubmed: 31153807.

9. Ljungman P, de La Camara R, Milpied N, et al. Valacyclovir International Bone Marrow Transplant Study Group. Randomized study of valacyclovir as prophylaxis against cytomegalovirus reactivation in recipients of allogeneic bone marrow transplants. Blood. 2002; 99(8): 3050-3056, doi: 10.1182/blood.v99.8.3050, indexed in Pubmed: 11929799.

10. Winston DJ, Yeager AM, Chandrasekar PH, et al. Valacyclovir Cytomegalovirus Study Group. Randomized comparison of oral valacyclovir and intravenous ganciclovir for prevention of cytomegalovirus disease after allogeneic bone marrow transplantation. Clin Infect Dis. 2003; 36(6): 749-758, doi: 10.1086/367836, indexed in Pubmed: 12627359.

11. Prentice HG, Gluckman E, Powles RL, et al. Impact of long-term acyclovir on cytomegalovirus infection and survival after allogeneic bone marrow transplantation. European Acyclovir for CMV Prophylaxis Study Group. Lancet. 1994; 343(8900): 749-753, doi: 10.1016/s0140-6736(94)91835-x, indexed in Pubmed: 7907729.

12. Goodrich JM, Bowden RA, Fisher L, et al. Ganciclovir prophylaxis to prevent cytomegalovirus disease after allogeneic marrow transplant. Ann Intern Med. 1993; 118(3): 173-178, doi: 10.7326/0003-4819118-3-199302010-00003, indexed in Pubmed: 8380242.

13. Winston DJ, Ho WG, Bartoni K, et al. Ganciclovir prophylaxis of cytomegalovirus infection and disease in allogeneic bone marrow transplant recipients. Results of a placebo-controlled, double-blind trial. Ann Intern Med. 1993; 118(3): 179-184, doi: 10.7326/0003-4819-1183-199302010-00004, indexed in Pubmed: 8380243.

14. Ordemann R, Naumann R, Geissler G, et al. Foscarnet-an alternative for cytomegalovirus prophylaxis after allogeneic stem cell transplantation? Ann Hematol. 2000; 79(8): 432-436, doi: 10.1007/ /s002770000189, indexed in Pubmed: 10985362.

15. Bregante S, Bertilson S, Tedone E, et al. Foscarnet prophylaxis of cytomegalovirus infections in patients undergoing allogeneic bone marrow transplantation (BMT): a dose-finding study. Bone Marrow Transplant. 2000; 26(1): 23-29, doi: 10.1038/sj.bmt.1702450, indexed in Pubmed: 10918402.

16. Chemaly RF, Ullmann AJ, Stoelben S, et al. AIC246 Study Team. Letermovir for cytomegalovirus prophylaxis in hematopoietic-cell transplantation. N Engl J Med. 2014; 370(19): 1781-1789, doi: 10.1056/ /NEJMoa1309533, indexed in Pubmed: 24806159.

17. Marty FM, Winston DJ, Rowley SD, et al. CMX001-201 Clinical Study Group. CMX001 to prevent cytomegalovirus disease in hematopoietic-cell transplantation. N Engl J Med. 2013; 369(13): 1227-1236, doi: 10.1056/NEJMoa1303688, indexed in Pubmed: 24066743.

18. Winston DJ, Young JAH, Pullarkat V, et al. Maribavir prophylaxis for prevention of cytomegalovirus infection in allogeneic stem cell transplant recipients: a multicenter, randomized, double-blind, placebo-controlled, dose-ranging study. Blood. 2008; 111(11): 5403-5410, doi: 10.1182/blood-2007-11-121558, indexed in Pubmed: 18285548.

19. Maertens J, Cordonnier C, Jaksch P, et al. Maribavir for Preemptive Treatment of Cytomegalovirus Reactivation. N Engl J Med. 2019; 381(12): 1136-1147, doi: 10.1056/NEJMoa1714656, indexed in Pubmed: 31532960.
20. Papanicolaou GA, Silveira FP, Langston AA, et al. Maribavir for refractory or resistant cytomegalovirus infections in hematopoietic-cell or solid-organ transplant recipients: a randomized, dose-ranging, double-blind, phase 2 study. Clin Infect Dis. 2019; 68(8): 1255-1264, doi: 10.1093/cid/ciy706, indexed in Pubmed: 30329038.

21. Chemaly RF, Hill JA, Voigt S, et al. In vitro comparison of currently available and investigational antiviral agents against pathogenic human double-stranded DNA viruses: a systematic literature review. Antiviral Res. 2019; 163: 50-58, doi: 10.1016/j.antiviral.2019.01.008, indexed in Pubmed: 30677427.

22. Shigle TL, Handy VW, Chemaly RF. Letermovir and its role in the prevention of cytomegalovirus infection in seropositive patients receiving an allogeneic hematopoietic cell transplant. Ther Adv Hematol. 2020; 11: 2040620720937150, doi: 10.1177/2040620720937150, indexed in Pubmed: 32637057.

23. Sharma P, Gakhar N, MacDonald J, et al. Letermovir prophylaxis through day 100 post transplant is safe and effective compared with alternative CMV prophylaxis strategies following adult cord blood and haploidentical cord blood transplantation. Bone Marrow Transplant. 2020; 55(4): 780-786, doi: 10.1038/s41409-019-0730-y, indexed in Pubmed: 31664185.

24. Lin A, Maloy M, Su Y, et al. Letermovir for primary and secondary cytomegalovirus prevention in allogeneic hematopoietic cell transplant recipients: real-world experience. Transpl Infect Dis. 2019; 21(6): e13187, doi: 10.1111/tid.13187, indexed in Pubmed: 31585500.

25. Derigs P, Radujkovic A, Schubert ML, et al. Letermovir prophylaxis is effective in preventing cytomegalovirus reactivation after allogeneic hematopoietic cell transplantation: single-center real-world data. Ann Hematol. 2020 [Epub ahead of print], doi: 10.1007/s00277-02004362-2, indexed in Pubmed: 33270162.

26. Anderson A, Raja M, Vazquez N, et al. Clinical "real-world" experience with letermovir for prevention of cytomegalovirus infection in allogeneic hematopoietic cell transplant recipients. Clin Transplant. 2020; 34(7): e13866, doi: 10.1111/ctr.13866, indexed in Pubmed: 32242979.

27. Milano F, Pergam SA, Xie Hu, et al. Intensive strategy to prevent CMV disease in seropositive umbilical cord blood transplant recipients. Blood. 2011; 118(20): 5689-5696, doi: 10.1182/ /blood-2011-06-361618, indexed in Pubmed: 21937692.

28. Styczyński J. Prophylaxis vs preemptive therapy in prevention of CMV infection: new insight on prophylactic strategy after allogeneic hematopoietic cell transplantation. Acta Haematol Pol. 2020; 51(1): 17-23, doi: 10.2478/ahp-2020-0005.

29. Ljungman P, Schmitt M, Marty FM, et al. A mortality analysis of letermovir prophylaxis for cytomegalovirus (CMV) in CMV-seropositive recipients of allogeneic hematopoietic cell transplantation. Clin Infect Dis. 2020; 70(8): 1525-1533, doi: 10.1093/cid/ciz490, indexed in Pubmed: 31179485.

30. Marty FM, Ljungman PT, Chemaly RF, et al. Outcomes of patients with detectable CMV DNA at randomization in the phase III trial of letermovir for the prevention of CMV infection in allogeneic hematopoietic cell transplantation. Am J Transplant. 2020; 20(6): 1703-1711, doi: 10.1111/ajt.15764, indexed in Pubmed: 31883426.

31. Styczyński J, Czyżewski K, Dębski R. Primary prophylaxis with letermovir for prevention of CMV infection in two children. Acta Haematol Pol. 2020; 51(4): 263-264, doi: 10.2478/ahp-2020-0046.

32. Styczyński J, Tridello G, Xhaard A, et al. Use of letermovir in off-label indications: Infectious Diseases Working Party of European Society of Blood and Marrow Transplantation retrospective study. Bone Marrow Transplant. 2021; 56(5): 1171-1179, doi: 10.1038/s41409-02001166-w, indexed in Pubmed: 33288863. 